Научная статья

УДК 811.161 .1

doi: $10.18101 / 2305-459 X-2021-1-8-15$

\title{
ГОМОГЕННЫЕ И ГЕТЕРОГЕННЫЕ СУБСТАНТИВНЫЕ МЕТАФОРЫ В ГОВОРАХ ЗАБАЙКАЛЬСКИХ СТАРООБРЯДЦЕВ (СЕМЕЙСКИХ)
}

\author{
(C) Дарбанова Надежда Александровна \\ кандидат филологических наук, доцент, \\ Бурятский государственный университет имени Доржи Банзарова \\ Россия, 670000, г. Улан-Удэ, ул. Ранжурова, 6 \\ ndarbanova@mail.ru
}

\begin{abstract}
Аннотация. Статья посвящена выявлению мотивации семантики экспрессивных лексико-семантических вариантов имен существительных, функционирующих в говорах забайкальских старообрядцев - семейских. Рассмотрены гомогенные и гетерогенные субстантивные метафоры, среди которых выявлены типы по мотивирующей семе - основанию метафорического переноса: ассоциативные, сущностные, сенсорные, утилитарные, функциональные и другие, а также модели «предмет $\rightarrow$ предмет», «человек $\rightarrow$ человек», «предмет $\rightarrow$ человек», «животное $\rightarrow$ человек», «физическое явление (болезнь) $\rightarrow$ человек». Гетерогенные субстантивные метафоры количественно преобладают над гомогенными. Субстантивные метафоры антропоцентричны, наиболее продуктивная модель - «предмет $\rightarrow$ человек». Регулярный тип метафорических переносов экспрессивных субстантивов - сущностные. Исследование подтверждает общность национально-культурных представлений семейских с другими группами русского народа и различие в реализации на лексическом уровне. Ключевые слова: говоры забайкальских старообрядцев - семейских; экспрессивные существительные; мотивация семантики метафор; гомогенные и гетерогенные метафоры.
\end{abstract}

\section{Для цитирования}

Дарбанова Н. А. Гомогенные и гетерогенные субстантивные метафоры в говорах забайкальских старообрядцев (семейских) // Вестник Бурятского государственного университета. Язык. Литература. Культура. 2021. Вып. 1. С. 8-15.

Цель статьи - выявить мотивацию семантики (основания переноса) экспрессивных лексико-семантических вариантов имен существительных, функционирующих в говорах забайкальских старообрядцев - семейских. Они проживают в Забайкалье со второй половины XVIII в., являются своеобразной этносоциальной группой русского населения. До сих пор их говор и культура отличаются от речи и традиций окружающего русского населения этого региона.

Актуальность обращения к данной проблеме обусловлена недостаточной изученностью в настоящее время экспрессивной лексики говоров забайкальских семейских, в частности их семантической мотивации: существует исследования автора данной статьи [3, 4, 6; и др.], между тем их нужно продолжать. Экспрессивные лексические единицы отражают отношение к миру данной конфессиональной группы и в целом представителей русской культуры. 
Н. А. Дарбанова. Гомогенные и гетерогенные субстантивные метафоры в говорах забайкальских старообрядцев (семейских)

Материал, представленный в статье, основывается на исследованиях автора, проведенных ранее [3], дополненных и переработанных. Одним из активных способов образования экспрессивных лексических единиц является метафоризация, так как известно, что в метафоре заложена оценочно-характеризующая роль, поэтому метафорический перенос является важным показателем экспрессивности таких единиц.

Метафоры образуются в результате взаимодействия семантических сфер [8; 9; и др.]. В зависимости от того, между какими семантическими сферами и в каком направлении осуществляется взаимодействие при метафорическом переносе, выделяют модели переносов: а) внутри семантических сфер, то есть в одной категории денотатов («предмет» $\rightarrow$ «предмет», «человек» $\rightarrow$ «человек»); б) между разными семантическими сферами («животное» $\rightarrow$ «человек», «предмет» $\rightarrow$ «человек», «предмет» $\rightarrow$ «физическое явление», «предмет» $\rightarrow$ «психическое явление», «предмет» $\rightarrow$ «отвлеченное понятие», «физическое явление» $\rightarrow$ «психическое явление») [8]. Мы назвали такие метафоры соответственно гомогенными и гетерогенными.

Гомогенные и гетерогенные метафоры подразделяем вслед за Н. Б. Лаврентьевой [7, с. 139-144] на типы по мотивирующей семе: 1) ассоциативные, в основе которых лежит обобщенное представление о данной реалии, 2) сущностные - характеризующие свойства личности, предмета, животного и др., принципы и свойства действий человека, артефакта, отражающие их сущность, 3) сенсорные: а) звуковые - обозначающие звуковые впечатления, б) зрительные - характеризующие внешний вид человека, животного, предмета и др., в) сенсорно-параметрические - обозначающие размер, параметры, 4) утилитарные - характеризующие эстетические и утилитарные свойства предметов, 5) функциональные - обозначающие функции предметов, 6) результативные - обозначающие результат действия, 7) целевые - характеризующие цель действия.

В говорах семейских среди субстантивных метафор с точки зрения тематической принадлежности исходной лексической единицы, подвергшейся метафорическому переосмыслению, то есть являющейся агентом метафоры, выделяются группы 'человек', ‘мифологический персонаж', ‘животное', 'предмет (артефакт)', 'растение (часть растения)', 'абстрактное действие, процесс', 'болезнь'. Референты метафор-существительных относятся к тематическим группам 'человек', 'предмет'.

Гомогенные субстантивные метафоры

а) Модель «предмет $\rightarrow$ предмет»:

Утилитарные метафоры (здесь и далее источником материала послужили словари $[10 ; 5])$ : дыгыл 1. 'длиннополая шуба из овчины, покрытая сукном или какой-нибудь другой тканью' (заимствование из бурятского дэгэл 'шуба, пальто' $[2$, c. 215]) $\rightarrow 2$. перен. ирон. 'одежда, не подходящая для данной ситуации' (основание переноса — 'несовременность', 'непрестижность'); чуни 1. 'самодельная обувь в виде кожаных чехлов, которые надевались поверх другой обуви (унтов, ичиг)' $\rightarrow 2$. 'о старой, изношенной, некрасивой, не соответствую- 
щей случаю обуви, а также обуви, которая по размеру больше необходимой 'ситуации' (основание переноса - 'несовременность', 'непрестижность', 'низкое качество изготовления', 'внешний вид'); черепки 1. 'обломки, осколки разбитого глиняного, фарфорового, фаянсового и т. п. изделия', 2. 'глиняная, а также другая обиходная посуда' $\rightarrow 3$. перен. О старой, некрасивой посуде (основание переноса - 'несовременность', 'непрестижность', 'низкое качество изготовления', 'внешний вид').

б) Модель «человек $\rightarrow$ человек»:

Сущностные метафоры: варнак устар. 1. 'человек, находящийся в заключении; преступник', 2. 'человек, бежавший из тюрьмы, с каторги' $\rightarrow$ 3. перен. ‘бездельник, хулиган', 4. перен. 'большой озорник, отчаянный шалун, проказник (обычно о ребенке)', 5. перен. 'безрассудно смелый, отчаянный, дерзкий человек' (основание переноса - 'специфика поведения'); вьюнош / вьюныш 1. 'молодой человек, юноша' $\rightarrow 2$. пренебр. О том, кто слишком молод для суждения о чем-л. (основание переноса - 'возраст, социальный статус'); тала 1. 'друг, товарищ (обычно о бурятах)' (в бурятском языке тала 'друг, приятель' [2, с. 411]), 2. 'бурят' $\rightarrow$ 3. перен. О недалеком, глупом, бестолковом человеке (основание переноса - 'принадлежность к другому этносу'); мума 1. 'немой человек' $\rightarrow$ 2. перен. 'о немногословном, необщительном, угрюмом человеке' (основание переноса $\rightarrow$ 'физические особенности').

Сенсорные (зрительные) метафоры: бамлак 1. 'человек, имевший судимость и отбывший заключение в БАМлаге', 2. 'человек, бежавший из тюрьмы, преступник', 3. перен. 'о неопрятном, неряшливом человеке' (основание переноса 'внешний вид'). Форма с финалью [к] свидетельствует о том, что данное слово воспринимается как немотивированное. Это обусловлено архаизацией исходного значения в связи с исчезновением реалии, в настоящее время лексема бамлак употребляется в одном ряду с номинациями мифологических существ букушка, букусетка, которыми пугают маленьких детей: «Вот бамлак тебя заберет!». Букусетка 1. 'по суеверным представлениям сверхъестественное существо, обитающее в бане, которым пугали детей' $\rightarrow 2$. перен. О нелюдимом, угрюмом, молчаливом человеке (основание переноса - 'сверхъестественное существо'); букушка 1. 'по суеверным представлениям сверхъестественное существо, которым пугают детей' $\rightarrow 2$. перен. О нелюдимом, угрюмом, молчаливом человеке (основание переноса - 'сверхъестественное существо').

Сущностные (звуковые) метафоры: гнуса 'говорящий в нос человек' $\rightarrow$ перен. О человеке, постоянно чем-л. недовольном, на что-л. жалующемся; нытике (основание переноса - 'звуковое впечатление от речи').

\section{Гетерогенные субстантивные метафоры}

a) Модель «предмет $\rightarrow$ человек»:

Сущностные метафоры: колун 1. 'тяжелый тупой топор для колки дров' $\rightarrow$ 2. перен. 'о недалеком, глупом, бестолковом человеке' (основания переноса 'тупой'); коржак 1. 'специально высушенный тонкий соленый хлебец из пресного теста' $\rightarrow 2$. перен. 'о скупом, жадном человеке' (основание переноса - 'высушенный, сухой’); веретёшка 1. 'веретено' $\rightarrow 2$. перен. О подвижной, непосед- 
Н. А. Дарбанова. Гомогенные и гетерогенные субстантивные метафоры в говорах забайкальских старообрядцев (семейских)

ливой девочке, девушке, женщине (основание переноса - 'подвижность'), крутелка/крутёлка 1. 'колодезный ворот' $\rightarrow 2$. перен. О ветреной, распутной женщине (основание переноса - представление о кручении, верчении как непостоянстве в отношениях), самопрядка/санопрядка 1. 'самопрялка' $\rightarrow 2$. перен. О чрезмерно говорливом человеке, пустослове (основание переноса - представление о кручении, верчении как непродуктивном действии, происходит возврат в исходную точку); шалаболка 1. 'то, что висит, болтается' $\rightarrow 2$. перен. О чрезмерно говорливом человеке, пустослове (основание переноса - представление о постоянном хаотическом движении как непродуктивном действии) $\rightarrow 3$. О подвижном, шаловливом ребенке (основание переноса - 'подвижность') $\rightarrow$ 4. перен. О ветреном, распутном человеке (основание переноса - представление о невекторном, хаотическом движении как непостоянстве в отношениях), шаркунец 1. 'колокольчик, бубенчик' $\rightarrow 2$. перен. О подвижном ребенке (основание переноса - 'подвижность'); находка 1. 'то, что случайно обнаружено, найдено (о предмете)' $\rightarrow$ 2. перен. 'внебрачный ребенок' (основание переноса — 'случайность обнаружения'); найда 1. 'то, что случайно обнаружено, тот, кто случайно обнаружен, найден (о предмете, животном)' $\rightarrow 2$. перен. 'внебрачный ребенок' (основание переноса — 'случайность обнаружения'); оскрёбыш, поскрёбыш, подскрёбышек 1. 'остатки, оскребки теста', 2. 'последняя булочка из остатков, оскребков теста' $\rightarrow 3$. перен. О младшем, обычно позднем, ребенке (основание переноса - 'из остатков').

Функциональные метафоры: ботало/ботал 1. 'изготовленный из железного или медного листа колокольчик, который подвешивается на шею коровам, лошадям, пасущимся без пастуха' $\rightarrow 2$. перен. О болтливом человеке, пустослове (основание метафорического переноса - функция предмета 'издавать звук', свойство 'бесполезность действия'), лагун 1. 'деревянный бочонок с двойным дном для хранения какой-л. жидкости и др.' $\rightarrow 2$. перен. 'пьяница' (основание переноса — 'вместилище, объем'), рогоза 1. 'палка с развилкой на конце; рогуля' $\rightarrow$ 2. перен. О неприступной, строгой девушке (основание переноса — 'колоть(ся)'), скобель 1. 'орудие в виде полукруглого ножа с ручками на концах для строгания вчерне или снимания коры с бревен' $\rightarrow 2$. перен. О злом человеке (основание переноса - функция 'нарушать целостность: срезать, строгать', свойство предмета 'способность поранить'); 3. перен. О ветреном, распутном человеке (основание переноса - свойство предмета 'способность поранить'); чеча 1. 'игрушка' $\rightarrow$ 2. перен. О лицемерном, притворно добродетельном человеке' (основание переноса - 'имитация человека, животного и др.').

Сенсорные (параметрические) метафоры: комяга 1. 'выдолбленное из цельного ствола дерева длинное корыто для поения и кормления лошадей' $\rightarrow 2$. перен. О толстом, неуклюжем, неповоротливом, неловком в движениях человеке (основание переноса - параметр 'значительный по размерам, величине', 'форма'), пупырёк 1. 'небольшая бутылка емкостью $1 / 4$ литра' $\rightarrow 2$. перен. О человеке небольшого роста (основание переноса — параметр 'незначительный по размерам, величине'), шкалик 1. разг. 'небольшая бутылка емкостью 1/4 литра' $\rightarrow 2$. перен. 
'человек невысокого роста' (основание переноса - параметр 'незначительный по размерам, величине').

Сенсорные (зрительные) метафоры: судомойка 1. 'тряпка или пучок травы для мытья посуды, пола и т. д.' $\rightarrow 2$. перен. О неряшливом, неопрятном человеке (основание переноса - 'внешний вид'); маковка 1. 'бумажный цветок мака, которым украшали кичку’ $\rightarrow 2$. перен. О нарядно одетой девушке (основание переноса — 'внешний вид').

Смешанные сенсорно-функииональные метафоры: пужало 1. 'огородное пугало' $\rightarrow$ 2. перен. О неряшливом, неопрятном человеке (основание переноса 'внешний вид', 'пугать своим видом').

Сущностные метафоры: лептюха 1. 'репейник' $\rightarrow 2$. перен. О назойливом, надоедливом человеке (основание переноса - свойство растения 'цепляться'); шипишка, шипишинка 1. 'растение шиповник' $\rightarrow 2$. перен. О насмешливом, язвительном человеке (основание переноса - свойство растения 'колоться'); хряпка 1. 'капустная кочерыжка' $\rightarrow 2$. перен. О большом, сильном, высокого роста и крепкого сложения человеке (основание переноса - 'крепкость').

б) Модель «животное $\rightarrow$ человек»:

Сущностные метафоры: мураш 1. 'муравей' $\rightarrow 2$. перен. О трудолюбивом, хлопотливом человеке; виноходка 1. 'иноходец' $\rightarrow 2$. перен. О человеке, имеющем особую походку: слишком раскачивающем бедрами при ходьбе (основание переноса - 'особая разновидность бега, отличающая иноходца от других видов лошадей'); гандыба 1. 'старая, больная лошадь; кляча' $\rightarrow 2$. перен. О неуклюжем, неповоротливом человеке (основание переноса - внешняя характеристика, физическое свойство 'старая, больная', поведение 'затрудненное движение'); пугач 1. 'филин' $\rightarrow 2$. перен. О нелюдимом, угрюмом человеке (основание переноса внешний вид, образ жизни, поведение птицы).

Aссоииативные метафоры: жимбура 1. 'суслик' (от бурят. зумбара, зумба$\operatorname{paa}(н)$ 'суслик' $[4$, с. 262]) $\rightarrow 2$. перен. 'ловкий, проникающий всюду путем хитрости, обмана человек' (основание переноса - негативное представление о поведении животного 'всюду проникать, приносить вред'), облайка 1. 'собака, которая обычно накидывается на людей с сильным лаем' $\rightarrow 2$. перен. О том, кто любит ругаться, постоянно грубо, крикливо ругается; о вздорном, сварливом человеке (обычно о женщине) (основание переноса — негативное представление о поведении животного 'часто беспричинно лаять' и звуковое впечатление от резкого отрывистого звучания лая собаки), тыкен 1. 'некастрированный самец домашней козы' (от бурят. тэхэ ‘козел (некастрированный)' [8, с. 458]) $\rightarrow 2$. перен. O безнравственном, похотливом, развратном мужчине, ведущем себя подобно тыкену (основание переноса - поведение животного), тымен 1. 'верблюд' (от бурят. тэмээ(н) ‘верблюд’ [8, с. 453]) $\rightarrow$ 2. перен. 'недалекий, грубый, бестолковый человек' (основание переноса - негативное представление о животном); росомаха 1. 'некрупное хищное животное семейства куньих с длинной, густой и грубой шерстью коричневато-бурого цвета и пушистым хвостом' $\rightarrow 2$. перен. О неопрятной, неряшливой женщине (основание переноса - негативное представление о животном); паровой 1. 'выращенный в инкубаторе (о птенце до- 
Н. А. Дарбанова. Гомогенные и гетерогенные субстантивные метафоры в говорах забайкальских старообрядцев (семейских)

машней птицы)' $\rightarrow 2$. перен. 'внебрачный (о ребенке)' (основание переноса 'выросший без участия родителей'); паровушка 1. 'выращенный в инкубаторе цыпленок' $\rightarrow 2$. перен. О внебрачном ребенке (основание переноса — 'выросший без участия родителей'); убоина 1. 'туша домашнего животного, заколотого на мясо' $\rightarrow 2$. перен. О неумелом, бестолковом человеке, не способном сделать чтол. хорошо, качественно (основание метафоры - свойство 'неподвижность').

в) Модель «физическое явление (болезнь) $\rightarrow$ человек»:

Метафоры следствия: кила 1. 'грыжа' $\rightarrow 2$. перен. О ворчливом человеке (основание переноса - 'проявление болезни'), кумуха 1. 'болезненное состояние человека, обычно сопровождающееся сонливостью', 'болезненное состояние человека, сопровождающееся жаром, ознобом; лихорадка // высыпания на губах при простуде, лихорадка' $\rightarrow 2$. перен. О ленивой, неумелой, неряшливой женщине (девушке, девочке) (основание переноса — 'поведение подобно человеку в болезненном состоянии'); и др.

Итак, в говорах семейских в гомогенных метафорах модели «предмет $\rightarrow$ предмет» реализуются признаки, характеризующие внешний вид предмета с точки зрения эстетичности, своевременности. Метафорический перенос, осуществляемый по гомогенной модели «человек $\rightarrow$ человек», основывается на рациональных признаках 'внешний вид', 'звуковое впечатление от речи', 'возраст', 'физические особенности' и др., используемых для характеристики внешнего вида, например бамлак; поведения, например варнак; социального статуса, например вьюнош/вьюныш; «внутренних» свойств личности - гнуса, принадлежность к другому этносу, реализация оппозиции «свой-чужой» — тала.

В говорах семейских гетерогенные субстантивные метафоры количественно преобладают над гомогенными. Такое соотношение закономерно: оно согласуется с выводом об актуальности моделей образования метафоры, в которых взаимодействуют денотаты разных семантических сфер [7-9]. Субстантивные метафоры в говорах семейских антропоцентричны $(74,5 \%)$, то есть строятся по общей модели «X $\rightarrow$ человек», в которой значение $\mathrm{X}$ переменно - 'животное', 'предмет', 'растение' и др., и характеризует психические, физические и связанные с социальным статусом свойства личности, особенности поведения. Наиболее продуктивная модель образования метафорических существительных — «предмет $\rightarrow$ человек» $(52,7 \%)$. Регулярный тип метафорических переносов семантически мотивированных экспрессивных субстантивов - сущностные. Большая часть метафор ассоциативного типа основывается на стереотипных представлениях о животных, частично отличающихся от общерусских представлений, что обусловлено спецификой существования данной группы населения в иноязычном окружении. Исследование подтверждает общность национально-культурных представлений семейских с другими группами русского народа, выраженных в семантике экспрессивных лексических единиц, поскольку семейские являются частью русского этноса, и незначительное различие в реализации на лексическом уровне, обусловленное территориальным членением языка. 
Лuтература

1. Дарбанова Н. А. Экспрессивная лексика говоров старообрядцев (семейских) Забайкалья (семантический, когнитивный и лексикографический аспекты): диссертация на соискание ученой степени кандидата филологических наук. Новосибирск, 2000. 200 с. Текст: непосредственный.

2. Дарбанова Н. А. Об отражении национальных стереотипных представлений в зооморфной лексике говоров забайкальских старообрядцев // Россия-Азия: становление и развитие национального самосознания: материалы международной научной конференции (21-23 июня 2005 г.). Улан-Удэ: Изд-во Бурят. гос. ун-та, 2005. С. 202-204. Текст: непосредственный.

3. Дарбанова Н. А. Образы движения в языковой картине мира старообрядцев Забайкалья (на материале экспрессивной лексики) // Вестник НГУ. Серия: История, филология / Новосибирский госуниверситет. Новосибирск, 2008. Т. 7, вып. 2. С. 10-15. Текст: непосредственный.

4. Скляревская Г. Н. Языковая метафора в словаре: опыт системного описания // Вопросы языкознания. 1987. № 2. С. 58-65. Текст: непосредственный.

5. Скляревская Г. Н. Метафора в системе языка. Санкт-Петербург: Наука, 1993. 152 с.

6. Лаврентьева Н. Б. Экспрессивно-выразительная глагольная лексика (на материале говоров Новосибирской области): диссертация на соискание ученой степени кандидата филологических наук. Томск, 1989. 206 с. Текст: непосредственный.

7. Словарь говоров старообрядцев (семейских) Забайкалья / Т.Б. Юмсунова, А. П. Майоров, Н. А. Дарбанова [и др.]; под ред. Т. Б. Юмсуновой. Новосибирск: Изд-во СО РАН, 1999. 540 с. Текст: непосредственный.

8. Дарбанова Н. А. Лексикографическое описание экспрессивной лексики говоров старообрядцев Забайкалья. Улан-Удэ: Изд-во Бурят. гос. ун-та, 2007. 223 с. Текст: непосредственный.

9. Черемисов К. М. Бурятско-русский словарь. Москва: Сов. энциклопедия, 1973. 80 с.

10. Арутюнова Н. Д. Языковая метафора (Синтаксис и лексика) // Лингвистика и поэтика. Москва, 1979. С. 147-173. Текст: непосредственный.

\section{HOMOGENEOUS AND HETEROGENEOUS SUBSTANTIVE METAPHORS IN SUBDIALECTS OF THE TRANSBAIKAL OLD BELIEVERS (SEMEISKIE)}

Nadezhda A. Darbanova

Cand. Sci. (Phil.), A/Prof.,

Dorzhi Banzarov Buryat State University

6 Ranzhurova St., Ulan-Ude 670000, Russia

ndarbanova@mail.ru

Abstract. The article identifies the motivation of the semantics of expressive lexicalsemantic variants of nouns functioning in subdialects of the Transbaikal Old Believers Semeiskie. We have considered homogeneous and heterogeneous substantive metaphors, and identified their types according to the motivating seme, i. e. on the basis of metaphorical transfer - associative, semantic, sensory, utilitarian, functional, etc., as well as the models — "object $\rightarrow$ object", "person $\rightarrow$ person", "object $\rightarrow$ human", "animal $\rightarrow$ human", "physical phenomenon (disease) $\rightarrow$ human ". Heterogeneous substantive metaphors quantitatively prevail over homogeneous ones. Substantial metaphors are anthropocentric, their most productive model is "object $\rightarrow$ person". The regular type of metaphori- 
Н. А. Дарбанова. Гомогенные и гетерогенные субстантивные метафоры в говорах забайкальских старообрядцев (семейских)

cal transfers of expressive substantives is semantic. The study confirms the similarity of national and cultural perceptions of Semeiskie and other groups of the Russian people, and the difference in their implementation at the lexical level.

Keywords: subdialects of the Transbaikal Old Believers - Semeiskie; expressive nouns; the motivation metaphor semantics; homogeneous and heterogeneous metaphors.

For citation

Darbanova N. A. Homogeneous and Heterogeneous Substantive Metaphors in Subdialects of the Transbaikal Old Believers (Semeiskie). Language. Literature. Culture. 2021; 1: 8-15 (In Russ.).

The article was submitted 27.01.2021; approved after reviewing 18.02.2021; accepted for publication 05.03.2021. 